\title{
Beyond the Numbers: on the road to achieving public value in community support organisations
}

\author{
F Girkin, E Shannon, C Zimitat and K Elliot
}

\begin{abstract}
Objective: To explore public value as a management tool for measuring outcomes, in Community Support Organisations (CSOs) and determine if further research is warranted.

Design: A literature review on public value and outcome measurement in the community service sector was conducted to evaluate how public value best fits with CSOs.

Setting: Public value has not previously been applied to measuring outcomes in CSOs and could provide beneficial information to assist in obtaining government funding as fiscal resources decline.

Main outcome measures: The following question was considered; Can a public value framework be used as a management tool by CSOs to measure the value of their service? A flow chart applying a public value framework to outcome measurement of CSOs was developed.
\end{abstract}

Results: Key elements identified were indicators, measures and outcomes. Stakeholders included; government, community sector, CSOs and consumer.

A public value framework has the potential to be used for measuring outcomes in the community sector however realworld application is still required.

Conclusion: This study provided preliminary application for a larger study and has provided evidence of a public value framework having the potential to be applied as an outcome measurement tool for CSOs.

Abbreviations: CSO - Community Support Organisation Key words: public value; community service; third sector; outcome measurement; community sector; outcomes; value.

\section{Fiona Girkin}

Centre for Rural Health,

University of Tasmania,

Launceston, Tasmania, Australia.

\section{Elizabeth Shannon}

School of Health Sciences,

University of Tasmania,

Launceston, Tasmania, Australia.

\section{Craig Zimitat}

Curtin Learning and Teaching,

Curtin University,

Perth, Western Australia, Australia.

\section{Kate-Ellen Elliot}

Wicking Dementia Research and Education, University of Tasmania School of Psychology, Hobart, Tasmania, Australia.

\section{Correspondence:}

fm.girkin@utas.edu.au

\section{Introduction}

Governments are responsible for producing public value through the services they provide and financially resource, such as non-government Community Service Organisations (CSOs) who generate value and social impact. [1] When public sector (government) services are outsourced to the private sector (non-government), government has not only outsourced the service but the delivery of public value. Public value can be defined as the value provided to society through the delivery of services [2] and can be generated by both private and public service delivery. [3] An understanding of public value, the common good for all citizens, [2] could assist CSOs by providing information on how services deliver value through service outcomes. This article examines literature on public value and outcome measurement to evaluate the viability of a Public Value Framework as a management tool for CSOs to better understand the value of delivered services. 
Mark Moore [4] first applied public value to public sector management to assist in creating value and trust within government by placing greater consideration on creatively and filling service gaps within current resources. CSOs funded by the government, are in a better position to deliver public value with more choice and flexible in meeting consumer needs and less constrained by political climates and broader citizen responsibilities. [5]

The key to measuring outcomes is understanding what and how, to measure what is being achieved. For example, if you wish to understand 'value for money' consider the financial investment compared to the client outcomes. If you wish to understand a services value from a client's prospective you would gather client feedback. Value can be measured from multiple perspectives, which Porter [6] highlighted as the most effective way to measure success. Outcomes can be evaluated at each level of service engagement and public value can be achieved by a combination of input from government, nongovernment and consumers.

Identifying key stakeholders and mapping outcomes are important components of understanding service value. [7] It is also important to clarify and define what you are hoping to measure and what would indicate the public value outcomes you have identified. [8] These indicators can then be used as a platform for understanding what to measure once the outcomes are defined. Outcomes occur as a result of services delivered and are essentially what can be achieved. [9] CSOs seek to provide services which improve emotional well-being and quality of life, such as; family violence services, neighbourhood houses, and family support.

\section{Method}

Literature was searched using related key words including; value, outcome measures and public value. Secondary words searched within key terms included healthcare, community organisations, outcome measures, well-being and value-based healthcare. These were searched in the following search agents; Informit, ProQuest, University of Tasmania library metasearch and Google. The literature was used to identify key elements for establishing a Public Value Framework.

\section{Results}

A comparison between public and private was articulated in Table 1 below as these terms are significant components of the framework and a comparison between how public and private service delivery contributes to public value.

In evaluating the literature, the following four elements were identified as required when establishing public value:

i. Indicators - Factors that demonstrate public value: economic value, client satisfaction, importance and benefit, quality and effectiveness and community functioning.

ii. Measures - Measurement questions used to evaluate public value at four levels of inquiry: government - Did the service funding provide value for money? Community Sector - Are we making a difference? CSO - Did we deliver an ethical service with integrity? Consumer Did the service I received improve my well-being?

iii. Outcomes - Achievements as a direct result of the service delivery.

iv. Trust - A key component which must be present for public value to be accomplished.

Table 1: Public and private difference and contributions to public value

\begin{tabular}{|l|c|c|} 
& PUBLIC (GOVERNMENT) & PRIVATE (NON-GOVERNMENT) \\
\hline FUNDING & Tax payer funded & Government funded \\
\hline INFLUENCE & Political & Organisation \\
\hline CONSTRAINTS & Public opinion and lack of funds & Funding requirements and political priorities \\
\hline FLEXIBILITY & Limited by political constraints & Adaptable to service \& individual needs \\
\hline PUBLIC VALUE \\
PROVIDED VIA
\end{tabular}




\section{Discussion}

The results provided insight into the key components of a Public Value Framework, however to understand how these components work together a flowchart of how the community services sector interacts was drafted (Figure 1) to inform the public value creation flowchart (Figure 2).

Figure 1: Community sector system: demonstration of how government and the community sector engage to provide support programs

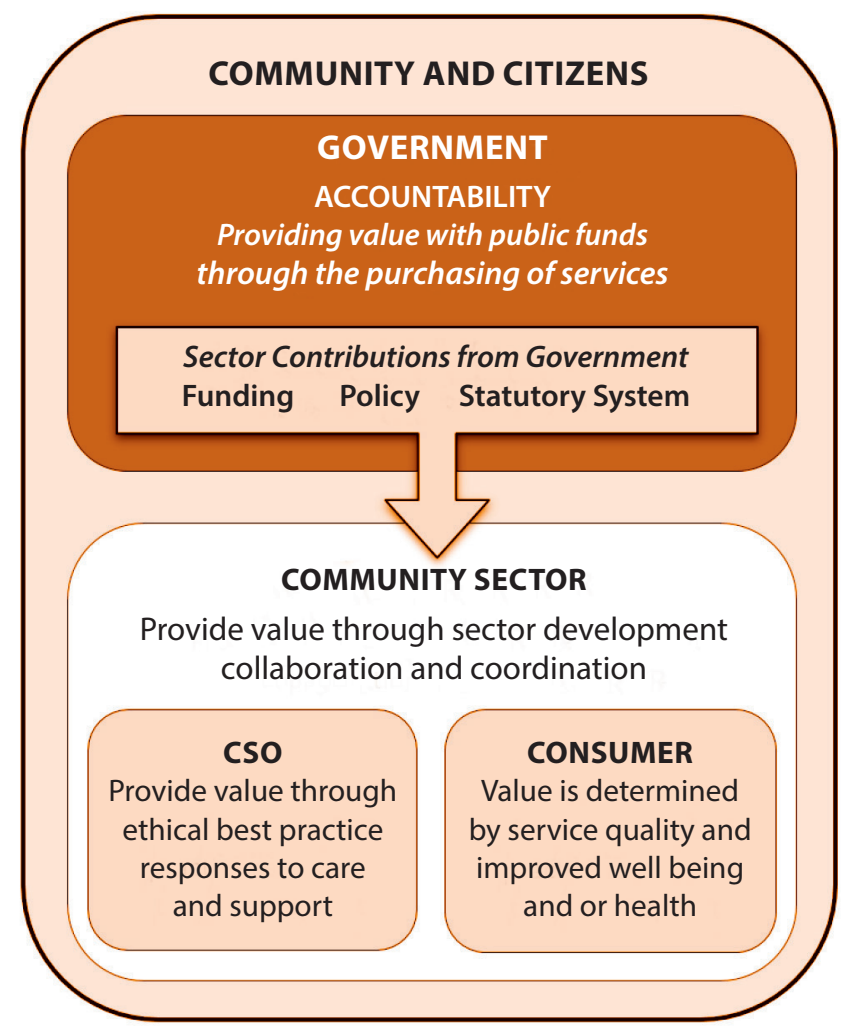

Figure 1 demonstrates the interactions between the key stakeholders and is considered in the context of how these would be applied to a small family violence service funded by the government to provide counselling to victims and survivors of violence. The government funder looking at value for money would need to compare the service with comparative family violence services of similar size, programs and funding type. The community sector level provides a more difficult challenge given that measuring a change in community functioning is often difficult and therefore this may include looking at community data that measures levels of family violence and whether this has been reduced. However, more work needs to be done to connect this back to the service and may involve looking at a variety of supports and community attitudes which may have contributed to the individual's outcome. The quality of the service delivered could be measured by looking at complaints and compliments, surveying or interviewing referring services as well as consumers. Consumers could also be interviewed about their experiences, which would provide data from a service user prospective.

A public value framework could be a useful tool for measuring the value of CSOs and the development of a flowchart (Figure 2) to show the path to public value was beneficial in providing a picture of how service outcomes can be mapped further than individual outcomes. There would be benefit in furthering the flowchart to show exactly how public value is provided at a community level (i.e. reduced family violence). Moreover, feedback can provide service and individual level improvement data whereas public value is the next step. So, the question that must be asked is; what is the flow on effect of the service provided? How is this then related back to public value? For example: an individual attends a family violence counselling service and the individual is satisfied with the service they received. When we look at public value we want to know what happened as a result of the service received beyond the individual. For example, the person had better health outcomes, improved family functioning and improved employability. Figure II highlights how outcomes lead to public value however another layer to this figure that lists outcomes beyond the service, as highlighted in the example (i.e. improved family functioning), would better capture the public value impact.

\section{Strengths}

A public value approach to the impact of CSOs could provide vital data for funding bodies to see the benefits their resources provide that may not have necessarily have been evident when looking at a service in isolation. The application of a public value framework to outcome measurement in the Community Sector provides a new level of understanding of the benefits, or lack thereof, that these services can provide to citizens. Moreover, given the many factors which contribute to an individual's well-being, this innovative approach could provide new information to assist in resource allocation by government decision makers.

\section{Weaknesses}

The flowchart (Figure 2) provides an overview of the process of collecting positive outcomes, nevertheless it appears to be lacking the element of identifying public value after outcomes are determined. This would include the use of external data such as demographic, health data and theories which identify the gaps and poor outcomes if a service was not in place. This process would mean combining CSOs data with much broader social data that could be open to interpretation by the CSO to improve their outcome results. 
Figure 2: Public Value Framework: Creating public value through CSOs

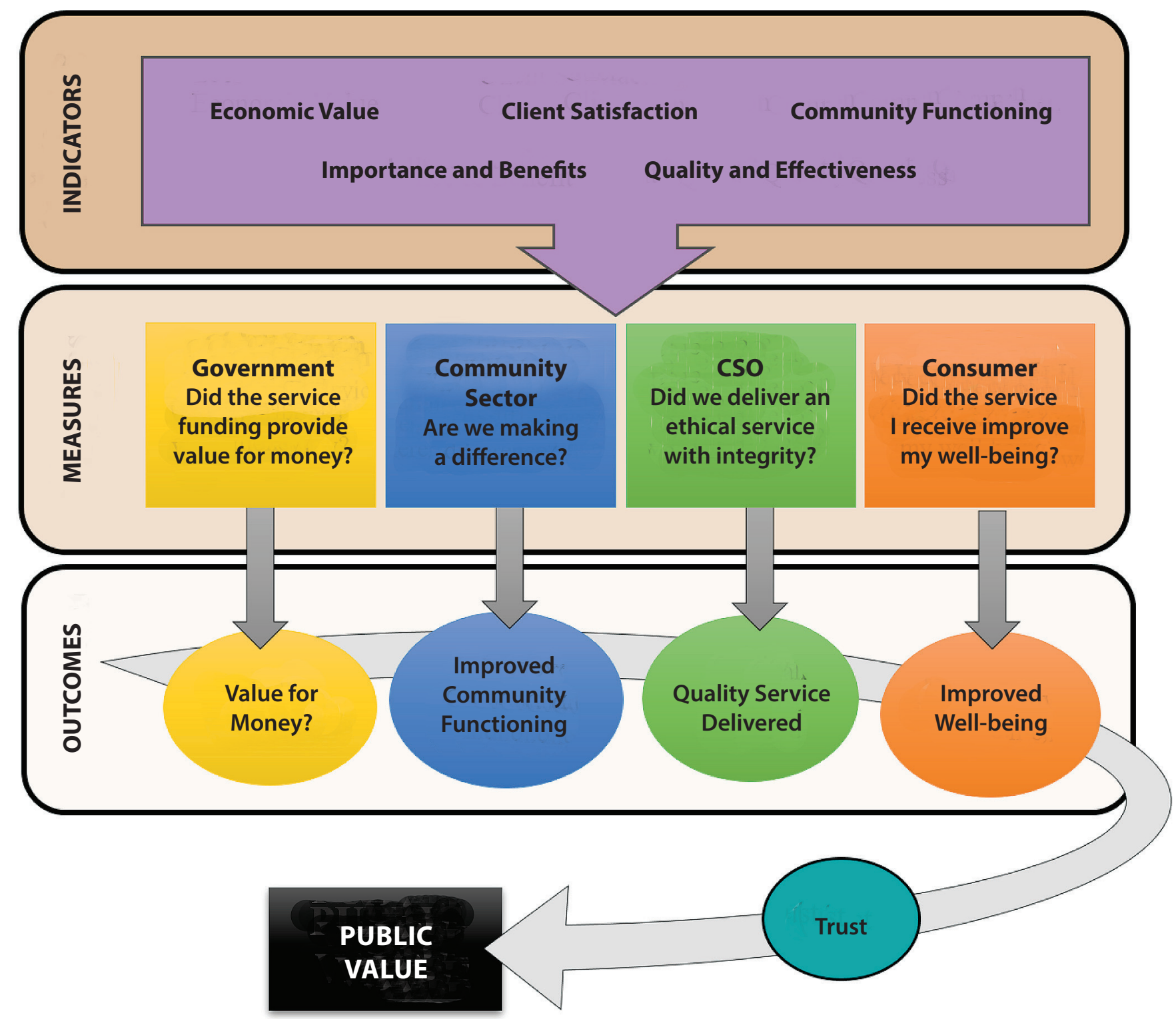

Hence if this approach was applied, the use of a subjective third party with no conflict of interest in the funding or the service may be useful to maintain transparency.

\section{Conclusion}

A public value framework has the potential to be used as a tool for measuring CSO outcomes and undertaking a larger study to test this approach against real CSO case studies would be beneficial. This project has highlighted that understanding the public value impact of CSOs could be a useful way to better understand the true impact government funded services provide to the community. This understanding could assist in how financial resources are directed toward improving community well-being where the most value is created. 'We live in a world where accountability has become an institution and where what gets measured gets valued ....' [10] and this has become especially true for the Community Sector. Therefore, understanding the true value provided by a service to the community, can ensure citizens receive the quality support they need.

\section{Competing interests}

The authors declare they have no competing interests.

\section{References}

1. Alford J, Hughes O. Public value pragmatism as the next phase of public management. The American Review of Public Administration. 2008;38(2):130-48.

2. Grant B, Tan S, Ryan R, Nesbitt R. Public Value Summary Background Paper Prepared for Local Governement Business Excellence Network (LGBEN). New South Wales: Australian Centre of Excellence for Local Government; 2014. 
3. Moore M. Recognizing public value. Cambridge, Mass: Harvard University Press; 2013.

4. Moore M. Creating public value : strategic management in Government. Cambridge, Mass: Harvard University Press; 1995.

5. O'Flynn J. From new public management to public value: paradigmatic change and managerial implications. Australian Journal of Public Administration. 2007;66(3): 353-66.

6. Porter M. What is value in health care? New Engl J Med. 2010; 363(26):2477-81.

7. Nicholls J, Lawlor E, Neitzert E, Goodspeed T. A guide to social return on investment. United Kingdom; 2012.

8. Muir K, Bennett $\mathrm{S}$. The compass: your guide to social impact measurement. Sydney: The Centre for Social Impact; 2014.

9. Wadia A, Parkinson D. Outcome and outcome indicator banks. London: Charities Evaluation Services; 2011.

10. Hadad S, Gauca O. Social impact measurement social entrepreneurial organizations. Management and Marketing Challenges for the Knowledge Society. 2014;9(2):119-36. 